\title{
Prediction of Outcome in Traumatic Brain Injury Based on Computed Tomography Scan
}

\section{ABSTRACT}

Introduction: Head injuries due to Road Traffic Accidents (RTA) succumbs nearly 1.3 million peoples every year on the roads worldwide. Due of its ability to accurately differentiate between the various forms of gross neuro-pathological lesions Computed Tomography (CT) scan remains the modality of choice for evaluating patients with head trauma.

Aim: To classify traumatic brain injuries using Marshall's classification and to predict their outcome using the Glasgow Coma Scale (GCS).

Materials and Methods: In this prospective study, 30 patients with history of recent head trauma of less than 24 hours were included. All the patients had undergone Non Contrast Computed Tomography (NCCT) of head and findings of the scan were noted and classified by Marshall's classification. The patients were followed for six months and their outcomes were recorded with GCS.

Results: Out of 30 patients with history of head trauma, $27(90 \%)$ of the patients were males, mostly in the age group of $21-40$ years with mean age being $32.4 \pm 21.65$ years. Twenty one $(70 \%)$ of the patient had contusions, $13(43.3 \%)$ of the subjects showed good prognosis with the outcome score of 5 . Most of the patients i.e. $11(36.7 \%)$ of the total subjects belonged to category III of Marshall's classification. Maximum morbidity $5(16.6 \%)$ and mortality $4(13.3 \%)$ were seen in class III of Marshall's classification.

Conclusion: NCCT scan is investigation of choice for diagnosing the brain injury and planning neurological intervention. Marshall's classification can help in aggressive neurological management of head injury patients according to score for good outcome.

Keywords: Glasgow coma outcome scale, Head trauma, Marshall's classification, Radiological imaging

\section{INTRODUCTION}

Traumatic brain injuries are most common cause of death and lifelong disability in early ages of life. Head injuries are second most common cause of death in today's world after cancer as $50 \%$ of the patients experiencing head trauma have unfavorable outcomes [1]. Road Traffic Accidents (RTA) and violence are main cause of head injuries in India and all over the world [2]. Head trauma can present as skull fractures, cerebral swellings, intracranial haematomas, pneumocranium, contusions and Diffuse Axonal Injuries (DAl). Low Glasgow Coma Scale (GCS) is common indication for imaging in head injuries [3]. Computerised Tomographies Scan (CT scan) promptly and accurately diagnose various brain abnormalities due to trauma and helps in proper management of these cases [4]. Role of CT scan in semiconscious and drowsy patient is substantial because of limitation of clinical and neurological examination in these patients as imaging further helps in planning neurological intervention at an early stage. The advantages of CT scan in head injuries are demonstration of mass effect, exact site and extent of fractures, acute cerebral haemorrhages, ventricular size and midline shift. Thus, CT scan acts as screening tool as well as first investigation of choice in all head injuries [5]. The purpose of present study was to predict outcome of traumatic brain injury in patients by the basis of CT scan findings.

\section{MATERIALS AND METHODS}

This prospective study was conducted in radiodiagnosis department of tertiary care teaching hospital over a period of 18 months from January 2017 to July 2018. Total 30 patients who presented in emergency department with history of recent head trauma of less than 24 hours were included for the study.

Informed written consent was taken from close relatives of patients as and when possible about the participation in present study. Ethical clearance for this study was granted by institute ethical committee (Letter no. SRHU/HIMS/ETHICS/59).

\section{Study Protocol}

All relevant details of history, general clinical examination findings, GCS score and other external injuries were recorded in case reporting form. All the patients had undergone NCCT of head using Siemens Somatom Sensation 64 slice multi detector CT machine. Contiguous axial $1.2 \mathrm{~mm}$ sections from base of skull to vertex were taken with parameters of $512 \times 512$ matrix, $130 \mathrm{KV}, 70 \mathrm{~mA}$. The scans were reviewed by senior radiologist.

The findings of the scan were noted and classified by Marshall's classification for traumatic brain injury [6]. The patients were followed up till six months and their outcome were recorded with the help of GCS [7].

\section{STATISTICAL ANALYSIS}

A database was constituted using freely available software solutions SPSS version 22 and electronic Microsoft Excel spreadsheets to store and manage the collected data. Association of categorical variables was analysed using Pearson's chi-square test. A p-value of $<0.05$ was considered significant.

\section{RESULTS}

Out of 30 patients, 27 (90\%) were males while 3 (10\%) were females with male to female ratio 9:1. Patient included in this study were from 2 years to 88 years with mean age being $32.4 \pm 21.65$ years. They presented to emergency department within 24 hours of head trauma earliest presenting in 60 minutes. Out of this 13 (43\%) were in the age group of 21-40 years followed by $8(27 \%)$ in $41-60$ years and $7(23 \%)$ were up to 20 years, while $2(7 \%)$ were more than 60 years of age. Soft tissue swelling was noted in 25 (83\%) of these patients while $5(17 \%)$ patients had no external swelling. On CT scan skull fracture was noted in 23 (77\%) patients, 21 (70\%) patient had contusion [Table/Fig-1], and 13 (43\%) patient had cerebral edema. Subarachnoid haemorrhage was seen in 14 (47\%) scans, 
subdural haematoma in 11 (37\%) scans and extradural haematoma in $7(23 \%)$ of scans. Each of intraventricular haemorrhage and pneumocranium [Table/Fig-2] was seen in 4 (13\%) scans while diffuse axonal injury was noted in $3(10 \%)$ scans. On Marshall's classification for traumatic brain injury, $11(37 \%)$ had Marshall score III, 7 (23\%) had Marshall score II while 5 (17\%) had Marshall score I [Table/Fig-3]. On GCS outcome score 13 (43\%) patients had good outcome score 5 , while 8 (27\%) patients had poor outcome score 1. On correlation of Marshall's classification maximum morbidity and mortality was seen in class III patients [Table/Fig-4]. On statistical

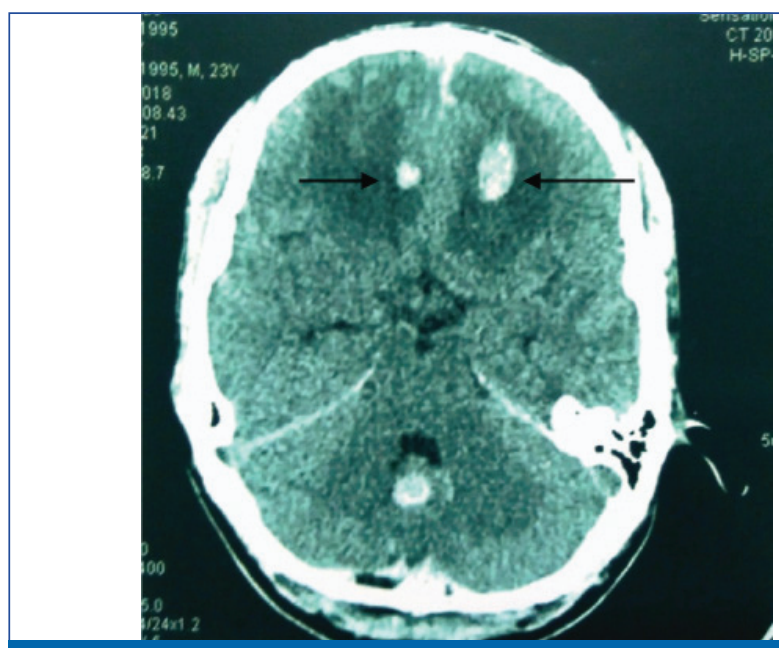

[Table/Fig-1]: NCCT head showing haemorrhagic contusion in bilateral frontal lobes (black arrows).

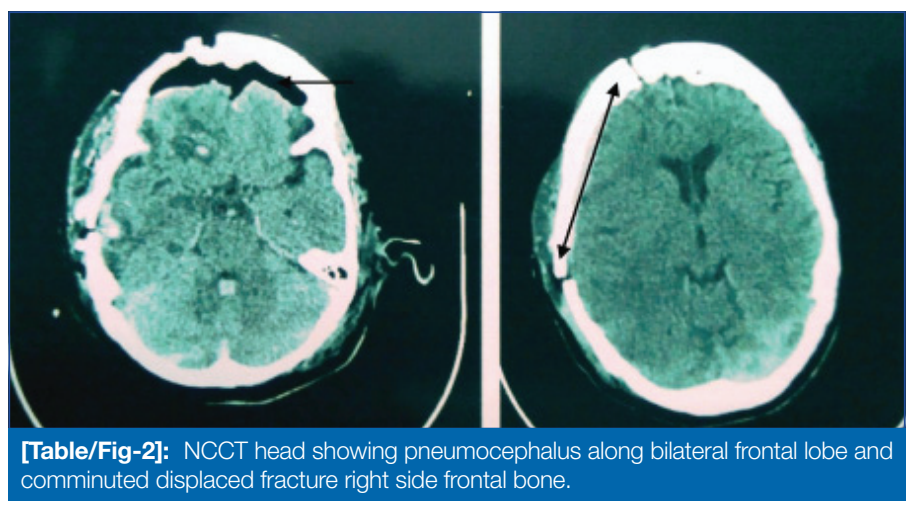

\begin{tabular}{|l|c|c|}
\hline Marshall classification & No. of patients & $\%$ \\
\hline I & 5 & 16.7 \\
\hline II & 7 & 23.3 \\
\hline III & 11 & 36.7 \\
\hline IV & 4 & 13.3 \\
\hline V & 3 & 10 \\
\hline VI & 0 & 0 \\
\hline Total & 30 & $100 \%$ \\
\hline [Table/Fig-3]: Marshall's classification of head injury patients. \\
\hline
\end{tabular}

analysis for correlating Marshall's score with GCS outcome score no significant statistical correlation was observed as $p$-value came out to be 0.864 [Table/Fig-4].

\section{DISCUSSION}

After the invention of CT scan in 1972 by GN Hounsfield, we can demonstrate abnormalities which were previously not possible even with invasive methods and further were detected only on autopsy [8]. In present study $90 \%$ head injuries occurred in males suggesting that head injuries are more common in male. This can be accounted as males are more commonly drive vehicles and most commonly involve in disputes. This study was in concordance by a study from Talwar IA and Jain V, where $80 \%$ were males and only $20 \%$ were females [9]. In present study, the majority of the people presenting to the emergency were in the age group of 21-40 years accounting to approximately $43.3 \%$. Gupta PK et al., reported $71 \%$ of head injury patient in the age group of 21-40 years in his study [10]. Haemorrhagic contusions were seen in $70 \%$ of the patient's scans. This correlated well with Alahmadi $\mathrm{H}$ et al., study, which showed haemorrhagic contusions to be the most common abnormality [11]. Subarachnoid haemorrhage was noted in maximum scans followed by subdural haematomas and extradural haematomas. This did not correlate well with the study by Murray GD et al., where SAH was seen in $20 \%$ of the subjects [12]. This might be due to small sample size in our study. In present study, it was also seen as the maximum number of subjects (36.7\%) was classified as Marshall's grade III and highest morbidity (16.6\%) and mortality (13.3\%) were also seen in this age group. This was not in concordance with the study by Maas Al et al., who found out maximum head injuries in the class II and the maximum morbidity and mortality was seen in the class IV [13]. In present study no significant statistical correlation was seen between the Marshall's classification and GCS outcome score as in our study, p-value came out to be 0.86 . This was probably due to low sample size of our study. However, our results are not in agreement by the results of Siahaan AMP et al., in which significant correlation was observed between Marshall CT score and 30 days GCS outcome score [14].

\section{LIMITATION}

Small sample size and small duration of follow-up are the limitations of present study.

\section{CONCLUSION}

There has been an increasing trend in the morbidity and mortality rates in cases of traumatic brain injuries. Most of the patients of acute head injury belongs to category III of Marshall's classification with highest morbidity and mortality. Marshall's classification can help in aggressive neurological management of head injury patients according to score for good outcome. No significant correlation was found between Marshall's classification and GCS in present study, so further study with larger size is warranted for traumatic brain injury patients.

\begin{tabular}{|c|c|c|c|c|c|c|}
\hline \multirow[b]{4}{*}{ Marshall classification } & \multicolumn{5}{|c|}{ GCS outcome score } & \multirow[b]{4}{*}{$p$-value } \\
\hline & \multirow{2}{*}{$\begin{array}{c}\text { Mortality } \\
1 \\
\end{array}$} & \multicolumn{3}{|c|}{ Morbidity } & \multirow{2}{*}{$\begin{array}{c}\text { Good recovery } \\
5 \\
\end{array}$} & \\
\hline & & 2 & 3 & 4 & & \\
\hline & Frequency (\%) & Frequency (\%) & Frequency (\%) & Frequency (\%) & Frequency (\%) & \\
\hline 1 & $1(20.0 \%)$ & $0(0.0 \%)$ & $1(20.0 \%)$ & $0(0.0 \%)$ & $3(60.0 \%)$ & \multirow{6}{*}{0.864} \\
\hline$\|$ & $1(14.3 \%)$ & $0(0.0 \%)$ & $0(0.0 \%)$ & $1(14.3 \%)$ & $5(71.4 \%)$ & \\
\hline III & $4(36.4 \%)$ & $1(9.1 \%)$ & $1(9.1 \%)$ & $3(27.3 \%)$ & $2(18.2 \%)$ & \\
\hline IV & $1(25.0 \%)$ & $0(0.0 \%)$ & $0(0.0 \%)$ & $1(25.0 \%)$ & 2 (50.0\%) & \\
\hline V & $1(33.3 \%)$ & $0(0.0 \%)$ & $0(0.0 \%)$ & $1(33.3 \%)$ & $1(33.3 \%)$ & \\
\hline Total & 8 (26.7\%) & $1(3.3 \%)$ & $2(6.7 \%)$ & $6(20.0 \%)$ & $13(43.3 \%)$ & \\
\hline
\end{tabular}




\section{REFERENCES}

[1] Sosin DM, Sniezek JE, Waxweiler RJ. Treands in death associated with traumatic brain injury, 1979 through 1992: Success and failure. JAMA. 1995;273(22):1778-80.

[2] Merino-deVillasante J, Taveras JM. Computerized tomography (CT) in acute head trauma. American Journal of Roentgenology. 1976;126(4):765-78.

[3] Fleischer AS, Payne NS, Tindell GT. Continuous monitoring of intracranial pressure in severe closed head injury without mass lesions. Surgical Neurology. 1976;6(1):31-34

[4] Saul TG, Joint section on Neurotrauma and critical care of the American association of neurological surgeons and Congress of neurological surgeons. Management of head injury: April 1998.

[5] National cancer institute USNloH. Radiation risks and peadiatric computed tomography: A guide for health care providers; 2002.

[6] Marshall LF, Marshall SB, Klauber MR, Clark MB, Eisenberg HM, Jane JA, et al. A new classification of head injury based on computerized tomography. $J$ Neurosurg. 1991;75:S14-S20.

[7] Teasdale G, Jannett B. Assessment of coma and impaired consciousness: A practical scale. The Lancet. 1974;304(7872):81-84.

[8] Zimmerman RA, Bilaniuk LT, Gennarelli T, Bruce D, Dolinskas C, Uzzell B. Cranial computed tomography in diagnosis and management of acute head trauma. American J Roentgenology. 1978;131(1):27-34.
[9] Talwar IA, Jain V. Computed tomography in recent head trauma. Independent J Rev. 1983;37(4):325-30.

[10] Gupta PK, Krishna A, Dwivedi AN, Gupta K, Madhu B, Gouri GS. CT scan findings and outcomes of head injury patients: A cross sectional study. Journal of Pioneering Medical Sciences. 2011;1(3):78.

[11] Alahmadi H, Vachhrajani S, Cusimano MD. The natural history of brain contusion: An analysis of radiological and clinical progression. Journal of Neurosurgery. 2010;112(5):1139-45.

[12] Murray GD, Teasdale GM, Dearden M, lannotti F, Lapierre F, Maas AJ, et al. Traumatic subarachnoid hemorrhage: Demographic and clinical study of 750 patients from the European brain injury consortium survey of head injuries. Neurosurgery. 2002;50(2):261-69.

[13] Maas Al, Hukkelhoven CW, Marshall LF, Steyerberg EW. Prediction of outcome in traumatic brain injury with computed tomographic characteristics: a comparison between the computed tomographic classification and combinations of computed tomographic predictors. Neurosurgery. 2005;57(6):1173-82.

[14] Siahaan AMP, Akbar TYM, Nasution MD. The role of Marshall and Rotterddam score in predicting 30 days outcome of traumatic brain injury. IOP conference series: Earth Environ Sci. 2018;125:012208.

PARTICULARS OF CONTRIBUTORS:

1. Senior Resident, Department of Radiodiagnosis, Swami Rama Himalayan University, Dehradun, Uttarakhand, India.

2. Associate Professor, Department of Radiodiagnosis, Swami Rama Himalayan University, Dehradun, Uttarakhand, India.

3. Professor, Department of Radiodiagnosis, Swami Rama Himalayan University, Dehradun, Uttarakhand, India.

\section{NAME, ADDRESS, E-MAIL ID OF THE CORRESPONDING AUTHOR:}

Dr. Mamta Goyal,

Associate Professor (Radiodiagnosis), HIMS, Swami Rama Himalayan University, Jollygrant,

Dehradun-248016, Uttarakhand, India.

E-mail: drmamta2712@rediffmail.com

FINANCIAL OR OTHER COMPETING INTERESTS: None.

Date of Submission: Jul 23, 2019 Date of Peer Review: Aug 26, 2019 Date of Acceptance: Sep 06, 2019 Date of Publishing: Oct 01, 2019 